\title{
Changes in Students' Participation and Small Group Norms in Scientific Argumentation
}

\author{
Sun Mi Yun • Heui-Baik Kim
}

Published online: 27 August 2014

(C) The Author(s) 2014. This article is published with open access at Springerlink.com

\begin{abstract}
The purpose of this study was to interpret students' participation in terms of social and argumentation norms to improve understanding of social interaction in scientific argumentation. Therefore, the study sought to identify social and argumentation norms formed in group argumentation and to explore changes in students' participation as lessons progressed. Twelve lessons that included argumentation were delivered to 44 eighth graders in Korea. In each lesson, small group argumentation tasks were introduced after the teacher had explained the main concepts or after student-centred hands-on activities. We analysed argumentation in one focus group based on various data, including audiotaped and videotaped conversations, field notes and student interviews. In early lessons, discussions were always teacher-initiated and led by a high-achieving student, while other students rarely presented ideas. Moreover, students struggled to seek answers in a textbook and often used analogies and common sense to explain phenomena. They tended to accept others' opinions unquestioningly or ignore other low achievers' ideas in small group argumentation. In later lessons, we observed studentinitiated and more equally distributed discussions, in which students were likely to make claims or statements actively based on experimental results and scientific knowledge. Along with these changes in discussion style, some students were seen to support the building of social norms and argumentation norms in a group. Also, performing tasks and receiving guidance from the teacher helped to build students' epistemological norms about scientific argumentation.
\end{abstract}

Keywords Scientific argumentation · Social norms · Argumentation norms · Small group argumentation $\cdot$ Participation

\section{Introduction}

A change of view with respect to whether learning results from an interactional process between the environment and a specific organism (Piaget 1977) or from a participatory process related to a community of practice or to community life (Vygotsky 1980) has led educators to highlight the sociohistorical context of knowledge construction. In sociocultural perspectives

S. M. Yun · H.-B. Kim $(\bowtie)$

Seoul National University, Seoul, Republic of Korea

e-mail: hbkim56@snu.ac.kr 
on learning, participation in discourse has been regarded as a primary characterisation of learning and knowing (Lave and Wenger 1991; Roth and Lawless 2002). In this sense, enhancing participation in discursive practices is learning itself and not simply something that supports learning (Anderson et al. 2007).

Argumentation is a central goal of science education, since it is a practice that joins the epistemic and conceptual aspects of science learning to the social aspects of scientific meaning making (Duschl 2008a, b). For this reason, the emphasis on scientific inquiry in science education has shifted from activities focusing on exploration and experimentation to central practices in which argument and explanation are constructed (Chin and Osborne 2010; Duschl et al. 2007). Given that students should be enculturated into scientific enterprise, argumentation has become an essential part of school science. For this reason, science educators have developed various teaching and learning strategies to implement scientific argumentation in a classroom and have explored the effects of these strategies on students' level of argument (e.g. Duschl et al. 1999; Erduran et al. 2004; McNeill 2009). Although these studies have shown that improving the level of argument is possible, a substantial body of research (e.g. Berland and Reiser 2009; Jiménez-Aleixandre et al. 2000; Sampson and Clark 2008; Sandoval and Millwood 2005) has reported that students' skills in employing evidence and constructing adequate arguments are somewhat limited, even with instruction that attempts to improve these skills.

A teacher-centred classroom culture and a lack of epistemic understanding of argumentation among students could explain why students sometimes struggle during the discursive practice of argumentation. Some researchers have indicated that students often fail to construct scientific arguments because of epistemic beliefs (Nussbaum and Bendixen 2003; Nussbaum et al. 2008). Other researchers (Berland and Reiser 2009; Ryu and Sandoval 2012) have insisted that students' failures in argumentation performance are also explained by their failure to perceive that persuasion is the purpose of argumentation in science classes. These results suggest that students' appropriation of the practices of the scientific community should be related to the social nature of scientific epistemology as well as to personal epistemology. Considering the sociocultural context dependence of learning, culture and norms established in student communities can affect students' practice of argumentation; therefore, students need support to learn appropriate norms for active participation in scientific argumentation.

In this study, we sought to identify group norms for constructing arguments in a small group, along with changes in these group norms, and to seek factors that encourage students' participation by connecting students' practice to group norms in group argumentation.

\section{Literature Review}

\section{Argumentation in Science Classrooms}

Science in schools is commonly portrayed from a 'positivist perspective' as a subject in which there are clear 'right answers'. Students are accustomed to accept unquestioningly scientific concepts provided by teachers or gleaned from a textbook. Students also tend to perceive science learning as acquisition of scientific knowledge. However, in a process of scientific knowledge construction, scientists review evidence carefully, evaluate alternative answers and try to prove their hypotheses. This scientific inquiry goes beyond simple experiments and includes a scientific communication process (Watson et al. 2004). Scientific knowledge is constructed within the scientific community and through social processes in which scientists' articles are usually reviewed and criticised by other scientists before being published in a 
journal. Argumentation plays quite an important role in the process of critical examination and evaluation (e.g. Bianchini 1997; Kelly and Crawford 1997; Richmond and Striley 1996).

Although many scholars have stressed that argumentation needs to be included in science education, studies of school science have unfortunately revealed that students were not substantively engaged in group discussions and argumentation (Newton et al. 1999; Driver et al. 2000). Thus, a number of studies have been conducted on how to expand argumentation opportunities and develop strategies to facilitate argumentation (e.g. Duschl et al. 1999; Erduran et al. 2004; McNeill 2009). Nevertheless, despite the emphasis on the ability to construct arguments in science teaching, Bennett et al. (2010) pointed out that students had difficulty constructing arguments and that they did not participate fully in small group discussion. By analysing students' argumentation, Berland and Reiser (2009) observed that students rarely participated in persuading others in argumentation. They suggested that students experienced no need to persuade others in traditional classroom interactions, during which teachers evaluated students' understanding of knowledge by listening to them summarising the right answer after a lesson and correcting them as needed. In other research, students' epistemic understanding of science was found to affect the nature of their argumentation (Nussbaum et al. 2008), and students' perceptions related to argumentation norms could be connected to their ability to identify fallacious arguments (Weinstock et al. 2004). In a study of classroom atmosphere, Jiménez-Aleixandre et al. (2000) observed that the teacher's efforts to encourage students to present and defend their ideas created a vibrant classroom atmosphere and led to collaborative problem solving and argumentation. Hence, it is necessary to examine students' community culture and norms in order to implement small group argumentation requiring social interaction in science classrooms. In the next section, we review the research on classroom norms, which play an essential role in learning.

\section{Classroom Culture and Norms}

Vygotsky's theory of social constructivism emphasises the internalisation of knowledge through interactions between students as well as between teachers and students (Driver 1995; Roth et al. 1999). Lave and Wenger (1991) viewed learning as a situational activity and emphasised a social process in which newcomers would go from peripheral to full participants in a community of practice. They also believed that learning should be grounded in social participation and interaction, both of which would play essential roles in terms of cognitive development and learning. Group activities require interaction between students, in which each student or student group tries to convince others of their point of view; however, this kind of interaction is always hindered in the teacher-centred classroom environment (Berland and Reiser 2009). Accordingly, Hogan (1999) argued that group norms needed to be explored, since group norms set the procedures and outcomes that were highly valued by the groups. Classroom culture is connected to conventional norms and may have an influence on the dynamics of knowledge construction. Thus, classroom culture needs to be understood if we are to implement argumentation in the context of the culture of the school and the students.

Although many researchers have emphasised the necessity of establishing and examining norms and culture in classrooms (Dixon et al. 2009; Driver et al. 2000; Ryu and Sandoval 2012; Weinstock et al. 2004; Yackel and Cobb 1996; Yerrick 2000), few have discussed what kind of norms should be formed for subject-specific purposes in classrooms. Furthermore, the idea that norms should be established for constructing arguments in a science classroom has not been comprehensively discussed in the literature. Yackel and Cobb (1996) introduced social norms, or general norms for students' participation, and sociomathematical norms, which consider the nature of a specific subject. Classroom social norms are general norms that 
apply to any subject area and are related to the general patterns of class activities. Sociomathematical norms relate to mathematics specifically and are defined as normative understandings of what counts as mathematically different, sophisticated, efficient and elegant (p. 461). Dixon et al. (2009), in a study on the effects of student-centred discourse on mathematical explanations, introduced new types of social and sociomathematical norms of which students need to be aware.

For argumentation to exist effectively in a science classroom, social norms that allow students to participate in a learning community must be established. In addition, it is crucial to establish norms for justifying scientific claims and persuading others in science classrooms so that scientific knowledge may be constructed in the classroom in the same way as in the scientific community. Therefore, we provide two kinds of norms required in students' small group argumentation and also define 'social norms' as general classroom norms related to the pattern of class activities, which include expectations of the roles and behaviour of teachers and students during these activities. 'Argumentation norms', specific to scientific argumentation, are collectively defined as an informal normative understanding that governs students' justifying claims or evaluating arguments in the light of evidence. Based on the above definition, this study aims to interpret students' participation in terms of social and argumentation norms to improve understanding of social interaction in scientific argumentation.

\section{Research Design and Method}

\section{Participants}

Participants were one teacher and 44 students (year 8) in a secondary school that is situated in a metropolitan area in Korea and has 28 classes with a total of 1,207 students. This school is ranked at a medium academic level in Korea. The teacher in the study was a science teacher who had 12 years of teaching experience in secondary school. She was unfamiliar with argumentation but was willing to implement argumentation in her lesson when researchers provided her with an instructional plan and the relevant resources. The participants were chosen from one of her eighth-grade classes. The class consisted of groups of four students of both sexes and mixed ability.

Among 11 small groups, one group (which showed the most active small group argumentation) was selected to be the major target, based on class observation and the teacher's recommendation and our wish to study a group that showed the biggest difference in their level of interaction from the beginning of the research to the later stages. We also based our selection of the group on the atmosphere in which discourse took place, offering minimal obstacles to communication. For example, groups in which some members were at odds and did not talk with one another were not chosen. The group selected consisted of two girls, St1 and St3, and two boys, St2 and St4. St1 showed the highest achievement in the midterm examination taken before the introduction of these tasks. The test scores of St2, St3 and St4 were in the middle, low and lowest achievement level in this school, respectively. Students were grouped according to these scores, with both high- and low-achieving students. Although more focus was directed earlier in the research towards the high-achieving students, we chose to analyse a small group with high interaction levels between group members during argumentation, as this was more aligned to our purpose to see what changes had taken place in students' participation and small group norms. 


\section{Study Context}

The lessons were conducted in a science lab, and all the students were seated in groups. At the beginning of each lesson, the teacher gave a brief introduction to the topic and explained the key scientific concepts or sometimes provided students with opportunities to do experiments. Students were introduced to scientific phenomena and were asked to construct an argument or to explain why the phenomenon occurred. They then compared each group member's argument or explanation and ultimately chose the most plausible idea to represent the group's opinion. We expected that students would learn how to convince others who had different opinions and justify their claims in the process of selecting the most plausible idea. At the end of each lesson, the teacher added explanations to help prevent students from forming misconceptions.

In order to foster small group argumentation activities, 12 tasks in the 'Structures and Functions of Plants' unit were devised and one task was introduced to the students in each lesson. Tasks that could be completed in 20 minutes were set in every lesson to familiarise students with argumentation, of which they had little previous experience. It took 4 weeks to conduct 12 tasks, and this relatively long period gave students opportunities to discuss their ideas and allowed researchers to explore group norms. The 12 tasks are shown in Table 1.

Some tasks were designed for students to make their own claims and justify them by providing evidence or evaluating alternative arguments. One example of these tasks is provided in the Appendix. In these tasks, we added sample statements (e.g. 'someone said, after looking at the results of an experiment, "A plant needs potassium, iron, sodium and chloride to grow."'), with which students were asked to agree or disagree, so as to facilitate argumentation. In order for students to make their own claims in this task, they would have to search the textbook for related topics, utilise the results of different experiments or look at illustrations. Also, students were given the opportunity to apply the information they had learned that day to help them structure their thoughts. The teacher assisted students by providing comments to them, making sure they understood the focus and directing them towards the necessary resources.

\section{Data Collection and Analysis}

We chose as our case study the group whose members all showed the most active participation in the later lessons. A transcript of this group's conversation was used for major data analysis in support of our in-depth examination of these students. Prior to the actual recording, some lessons had been recorded in an attempt to overcome students' reluctance to being videotaped. In addition to the lesson observation notes, student-written arguments and interview data (semi-structured and supplementary interview data) were utilised to better understand the context.

Data analysis comprised two main parts: students' participation and small group norms. Students' participation was analysed by observing the function of student utterances. We also analysed how students participated both in the early and later lessons from the perspective of legitimate peripheral participation (Lave and Wenger 1991). Toulmin's Argument Pattern (TAP) has been used by researchers as a methodological tool for evaluating the quality of argumentation (Toulmin 1958). However, TAP poses difficulties in the interpretation and identification of argument elements (Kelly et al. 1998). In addition, some researchers are concerned that TAP is inappropriate when analysing real dialogic argumentation, as there is no recognition given to the interactional aspects of argument or to the fact that arguments are generally influenced by their linguistic and situational context (Duschl 2008a; Duschl et al. 1999). Therefore, we used the analytic framework of Park and Kim (2012) to analyse the function of students' utterances during small group argumentation, with a view to analysing 
Table 1 Task topics and activities in each lesson

\begin{tabular}{ll}
\hline Lesson & Task topic \\
\hline 1 & Task 1 \\
& How do features of plant roots in a dry area \\
differ from those in a humid region? \\
Task 2 \\
Why does a plant die when you fertilize it too \\
much?
\end{tabular}

Activity

Do you agree with the sample statement about result of buckwheat's growth?

\section{Task 4}

Do you agree with the sample statement about the presence of organic matter in the plant?

Task 5

What can you deduce from the experiment about the stem's functions?

\section{Task 6}

What are the differences between monocot plants and dicot plants?

Do you agree with the sample statement about what makes changes in a girdled stem?

Task 8

Which is upside of the leaf in the microscopic picture of a cross-sectioned leaf?

What will happen to the transpiration devices?

10
Task 10

Why did some changes occur in the transpiration devices?

\section{Task 11}

Where does photosynthesis take place?

\section{Task 12}

What would happen if a petri dish containing spirogyra and aerobic bacteria were placed in either a light place or a dark place?
Make claims and justify them with reasons why you select the features.

Choose the most plausible argument in the group.

Make explanations and justify them with evidence.

Choose the best argument in the group by evaluating peers' explanations.

State your agreement or disagreement, with reasons.

Try to persuade opponents with reasons.

Choose the most plausible argument in the group.

State your agreement or disagreement, with reasons.

Try to persuade opponents with reasons.

Choose the most plausible argument in the group.

Make explanations and justify them with empirical evidence.

Choose the best argument in the group by evaluating peers' explanations.

Make explanations and justify them with empirical evidence.

Choose the best argument in the group by evaluating peers' explanations.

State your agreement or disagreement, with reasons.

Try to persuade opponents with reasons.

Choose the most plausible argument in the group.

Make claims and justify them with evidence.

Choose the best argument in the group by evaluating peers' arguments.

Make claims and justify them with reasons which predict those changes.

Choose the most plausible argument in the group.

Make explanations and justify them with evidence.

Choose the best argument in the group by evaluating peers' explanations.

Make explanations and justify them with evidence.

Choose the best argument in the group by evaluating peers' explanations.

Make explanations and justify them with evidence.

Choose the best argument in the group by evaluating peers' explanations.

their participation. Park and Kim (2012) classified student utterances according to their contributions to the quality of argumentation (Table 2). We defined a student utterance unit as being bounded by the pause that is caused when another student interrupts the student's speech or when the student finishes his/her own statements. All utterances were analysed by the first author. To establish reliability, a second coder who is an expert in science education independently coded the utterances in three lessons (around $25 \%$ of utterances) selected among 12. Our estimates of inter-rater reliability were calculated by percentage of agreement. A level of agreement between the two coders of $94.6 \%$ was obtained. The reliability was leveraged with all disagreements resolved through discussion, and all the utterances of 12 lessons were checked again by the first author. 
Table 2 Analytic framework of students' utterances

\begin{tabular}{|c|c|c|}
\hline Code & Function & Utterance example \\
\hline Introducing & Start of discussion & $\begin{array}{l}\text { Let's discuss. } \\
\text { Do you agree? }\end{array}$ \\
\hline Responding & Responding to questions (passive) & I disagree. I agree. \\
\hline Adding & $\begin{array}{l}\text { Presenting additional explanation } \\
\text { to a previous opinion in order to } \\
\text { show agreement }\end{array}$ & $\begin{array}{l}\text { The water flow is blocked as the blood vessels are } \\
\text { clogged. }\end{array}$ \\
\hline Tuning & Simple comments on previous idea & $\begin{array}{l}\text { That's right. } \\
\text { Sure. } \\
\text { I believe St1 wrote the best answer. }\end{array}$ \\
\hline Ignoring & Ignoring others' ideas & $\begin{array}{l}\text { What are you talking about? } \\
\text { Don't be a fool. }\end{array}$ \\
\hline Extending & $\begin{array}{l}\text { Extending discussed idea considering } \\
\text { alternatives }\end{array}$ & It's just like when people die of diabetes. \\
\hline Synthesizing & Synthesizing group members' ideas & You think like this, he thinks...I think... \\
\hline Clarifying & $\begin{array}{l}\text { Stating clarified opinion with evidence } \\
\text { and reasoning }\end{array}$ & $\begin{array}{l}\text { I think overusing fertilizers kills the plant because } \\
\text { it makes the soil more concentrated... }\end{array}$ \\
\hline Requesting & Requesting further explanations & So, why is that? \\
\hline Skeptical & Presenting doubts to other's ideas & $\begin{array}{l}\text { This does not mean plants have iron. That means } \\
\text { plants need it. }\end{array}$ \\
\hline Refuting & $\begin{array}{l}\text { Stating clarified refutation of opposite } \\
\text { opinions }\end{array}$ & $\begin{array}{l}\text { That is not true because plant growth in D where } \\
\text { sodium and chloride are added is similar to that } \\
\text { of A which contains normal media. }\end{array}$ \\
\hline
\end{tabular}

Based on grounded theory, small group norms were inductively analysed using the data collected from videotaping, voice recording and interview transcriptions. We reviewed the literature and narrowed down the norms that frequently occurred in small group activities. We then analysed interview data and field notes to make a categorisation of social and argumentation norms. In the end, we increased the validity of the data analysis by reinterpreting small group norms and argumentation in a small group discourse context, and all the data were revised and supplemented by consultation with experts.

\section{Results}

Student participation patterns as well as social norms and argumentation norms in a small group were found to have changed during the course of working through the 12 tasks. In this section, key features of early and late lessons will be presented.

Early Lessons

\section{Students' Participation}

In the second lesson, students were asked to explain 'why a plant died when you fertilised it too much' and evaluate peers' explanations through discussions in small groups in the process of choosing the best explanation in a group. After presenting this task, the teacher moved around the classroom and instructed students not to copy one another but to write down their thoughts about the question, which should be logical as well as reasonable and be based on 
what they had learned during the lesson. While doing so, the teacher noticed groups not engaged in discussions after writing down their answers. The teacher encouraged groups that were not participating in discussion by asking, 'Why are you not talking to one another? Freely share your opinions with your peers.' This helped students to kick-start their discussion amongst group members. The teacher addressed some students who simply just wrote their claims without any evidence by saying, 'Think about the connection with the experimental results and observations that you collected as a source of evidence to structure your claim.' After she had given them a little encouragement, the students began to participate in sharing their thoughts. As can be seen in the small group argumentations below (Table 3), St1 started stating her opinions as soon as the teacher asked them to share opinions in the group. She explained the scientific phenomenon using her knowledge of osmosis, which was the theme of that lesson. St2 then also tried to explain that the plant's death seemed to be just like a human being developing diabetes (he might think that, just as a high concentration of blood sugar causes diabetes, so an excess of fertiliser could cause plant disease and death), but his argument was constantly interrupted by St1, and he was frustrated with his peers (see lines 2-7). St2 was opposed to St3's claim that St1's explanation was the best, even though it was

Table 3 Small group argumentation in the second lesson

\begin{tabular}{|c|c|c|}
\hline Line & Student utterances & Code \\
\hline & (The teacher approaches the student) Please have a discussion. & Introducing \\
\hline 1 & $\begin{array}{l}\text { St1: (Looking at her written argument) I think overusing of fertilizers kills the plant because } \\
\text { it makes the soil more concentrated compared to the concentration of the plant, causing } \\
\text { the extraction of water from the plant to the soil which dries up and kills the plant. }\end{array}$ & Clarifying \\
\hline 2 & St2: It's just like when people die of diabetes. & Extending \\
\hline 3 & St1: No, it isn't... & Ignoring \\
\hline 4 & St2: [It's the same because] the vessels get clogged. & Adding \\
\hline 5 & $\begin{array}{l}\text { St1: (Impatiently speaking) The problem is not clogging; the plant dies because of } \\
\text { dehydration. }\end{array}$ & \\
\hline 6 & $\begin{array}{l}\text { St2: Yeah, [The plant dries up] because the water flow is blocked as the blood vessels } \\
\text { are clogged. }\end{array}$ & Adding \\
\hline 7 & St1: Don't be a fool. (other students laughing) & Ignoring \\
\hline 8 & St3: I believe St1 wrote the best answer. & Tuning \\
\hline 9 & St2: I disagree with St1. & Ignoring \\
\hline 10 & $\begin{array}{l}\text { St1: (Pointing out the note) It is osmosis; water moves from low concentration to high } \\
\text { concentration. }\end{array}$ & Adding \\
\hline 11 & St2: I disagree with St1. We don't have to give her a right to speak. & Ignoring \\
\hline 12 & St1: What are you talking about? Forget it!! & Ignoring \\
\hline 13 & $\begin{array}{l}\text { St2: Let's decide the presenter by playing rock-paper-scissors. (others did not pay attention } \\
\text { to his words) }\end{array}$ & \\
\hline 14 & St2: Hey guys, We're going to choose the presenter using rock-paper-scissors. & \\
\hline 15 & St3: No! & \\
\hline 16 & St1: Maybe our group is not going to present. & \\
\hline 17 & $\begin{array}{l}\text { St2: Whoever doesn't play the game will be the presenter, rock-paper-scissors! You didn't } \\
\text { show anything. Hahaha! (boys laughing) }\end{array}$ & \\
\hline 18 & St1: (Annoyed) I say we may not be chosen to present. & \\
\hline 19 & St2: (Annoyed) That's why we have to decide now. & \\
\hline 20 & St1: Okay, rock-paper-scissors! & \\
\hline
\end{tabular}


more elaborate than his explanation, and he strongly advocated playing rock-paper-scissors to choose one person to present the group's opinion (see lines 9-19). The student utterances show that they tended to ignore other opinions, instead of sharing opinions and justifying their choice of claims with a reason. St1 was the only one who got the chance to state her opinion with evidence (see line 1), while St3 simply commented on others' argumentation and St4 did not even contribute to the group argumentation.

In the third lesson, a sample statement about the result of buckwheat hydroponics was given to the students to discuss (see Appendix). After a few minutes, the teacher saw that students were hesitating to write their personal opinions down, so she addressed the whole class, saying, 'There is no one correct answer. The thoughts you write down could be the right answer, so don't feel any pressure to write a statement; you should write down ideas in a logical and reasonable way, based on what you learned in the lesson.' When the teacher approached the target group and encouraged them to discuss, the two boys did not show any response, even though the girls asked for their opinions. The teacher told the whole class to discuss and St1 started talking about her opinion, after which the group argumentation began. St1 suggested that sodium and chloride have nothing to do with the growth of the plant because there is no difference in the buckwheat grown in various culture media. St3 and St4 agreed, while St2 opposed St1's opinion. However, St2's opinion on the experiment's conclusion was founded on a general interpretation, namely, that the lacking element will eventually result in symptoms of deficiency. St2's opinion was contradictory to the experimental results, so St1 and St3 refuted his argument by providing evidence. As in the second lesson, only St1 made utterances that enhanced students' reasoning, while St 3 and St 4 were more likely to be convinced by St1, rather than stating their own opinions.

In the fourth lesson, St1 was also the first to share her opinion, which was based on applying the knowledge that she had learned in the previous lesson, while the two boys said only, 'I wrote down the same thing', without presenting specific opinions. St2 said, 'So, let's just choose St1 as the presenter, since we wrote the same opinions', and St4 agreed with St2, attempting to end the discussion. In this activity, students were more likely to present a simple response (such as Tuning and Responding), which was a relatively low cognitive level type of utterance (see Table 2).

Lave and Wenger (1991) defined novices as those who are new in communities of practice and are not yet sufficiently skilled to make decisions or solve problems as legitimate peripheral participants. In the early lessons of this study, three students in the target group showed peripheral participation in the discussion. Although all students were legitimate members of the group, they did not respect others as members. They did not try to state their own opinions, and other students' ideas were frequently ignored. Unlike these three students, St1 was more likely to participate in the activities.

\section{Social Norms}

From the students' discourses and behaviour in lessons $2-4$, we inferred the existing small group social norms. The first norm identified was that students would start a discussion in a group when the teacher asked them to do so. We observed that group argumentation was mainly initiated by the teacher and that the students did not tend to get involved in discussion, even after they had finished writing down their arguments. Instead, they spent time talking about TV shows and games. Second, a high-achieving student had to lead discussions and be responsible for presenting opinions. In early lessons, we noticed students depending on St1. For example, while writing down their own thoughts, others tried to copy what St1 wrote or to ask her what she had written down. The students seemed always to confirm her opinion before 
making their own judgments. St1 invariably started the discussion, indicating that she had the authority to regulate the group argumentations. When interviewed, Stl said, 'The other students have the impression that I am right and my opinion is right. So I tried hard to meet their expectations, even if sometimes I don't know the answers (laughing).' Third, students thought it would be better to keep quiet if they did not know what to say. Most students tended to be reluctant to express their opinions, despite the teacher's repeated assurance that there was no one correct answer and that the important thing was to write down their thoughts. In particular, low-achieving students, such as St3 and St4, neither wrote down others' opinions nor stated their own opinions. Additionally, St2, who had presented his opinions in the second and third lessons, just accepted St1's opinion in the fourth lesson. St2's passive participation in the fourth lesson can be expected from his statement in the third lesson that, 'I was totally a fool today. You know, I was pretending to be a fool.' A student may be reluctant to actively participate in a group activity if he or she had previously had a negative experience and was worried about losing the trust of the group (Blatchford and Baines 2010).

\section{Argumentation Norms}

Three common features were found in terms of argumentation norms. First, students believed that they should find the correct answer the teacher expected, rather than making their own claims and evaluating peers' claims regarding the data. They tended to look in the textbook when they worked individually, believing that the right answer would be contained there, and they needed only to copy it down. In addition, students did not pay attention to their peers' presentations and instead just corrected their answers when the teacher reviewed the whole lesson at the end of the lesson. Even a high-achiever, St1, in her interview, showed that she focused on determining correct answers rather than justifying claims by providing evidence. 'They [peers] first wrote answers by themselves and I could see wrong answers. So I had to let them know their mistakes and they just corrected their answers.' Second, students did not have a normative understanding of how to evaluate peers' claims and make the group's argument. Instead of using evidence to explain why a particular answer was the best, students opted for a game of chance (rock-paper-scissors) to choose the presenter and the group's argument. Third, students strongly believed that 'someone's argument would be right if it included information from the textbook'. In this study, St1 was more likely to use the knowledge that she had learned, and others trusted her opinion and accepted it. In the fourth lesson, when the teacher asked St3, 'Who wrote the most convincing answer?', St 3 answered, 'St 1 did a good job using the knowledge that we learned.' Last, even when students tried to justify their claims, they used analogies or common sense to support them. St2's statements, such as 'It's just like how people die of diabetes' and 'If the plant is lacking one element, plant growth will be affected', are examples. Similar tendencies were also found in the study of Hogan and Maglienti (2001): Students were likely to adopt their personal views when they drew conclusions. This shows that students lack an understanding of how to provide evidence to justify their positions.

\section{Late Lessons}

\section{Students' Participation}

The task of the eighth lesson was to identify, using both theory and reasoning, which was the top side of a leaf in microscope photos of a cross section of a leaf (Table 4). Surprisingly, it was neither the teacher nor St1 but St3 who started the discussion in this lesson. St3 repeatedly asked other students their opinions (see lines1-7) and encouraged students who were hesitant 
Table 4 Small group argumentation in the eighth lesson

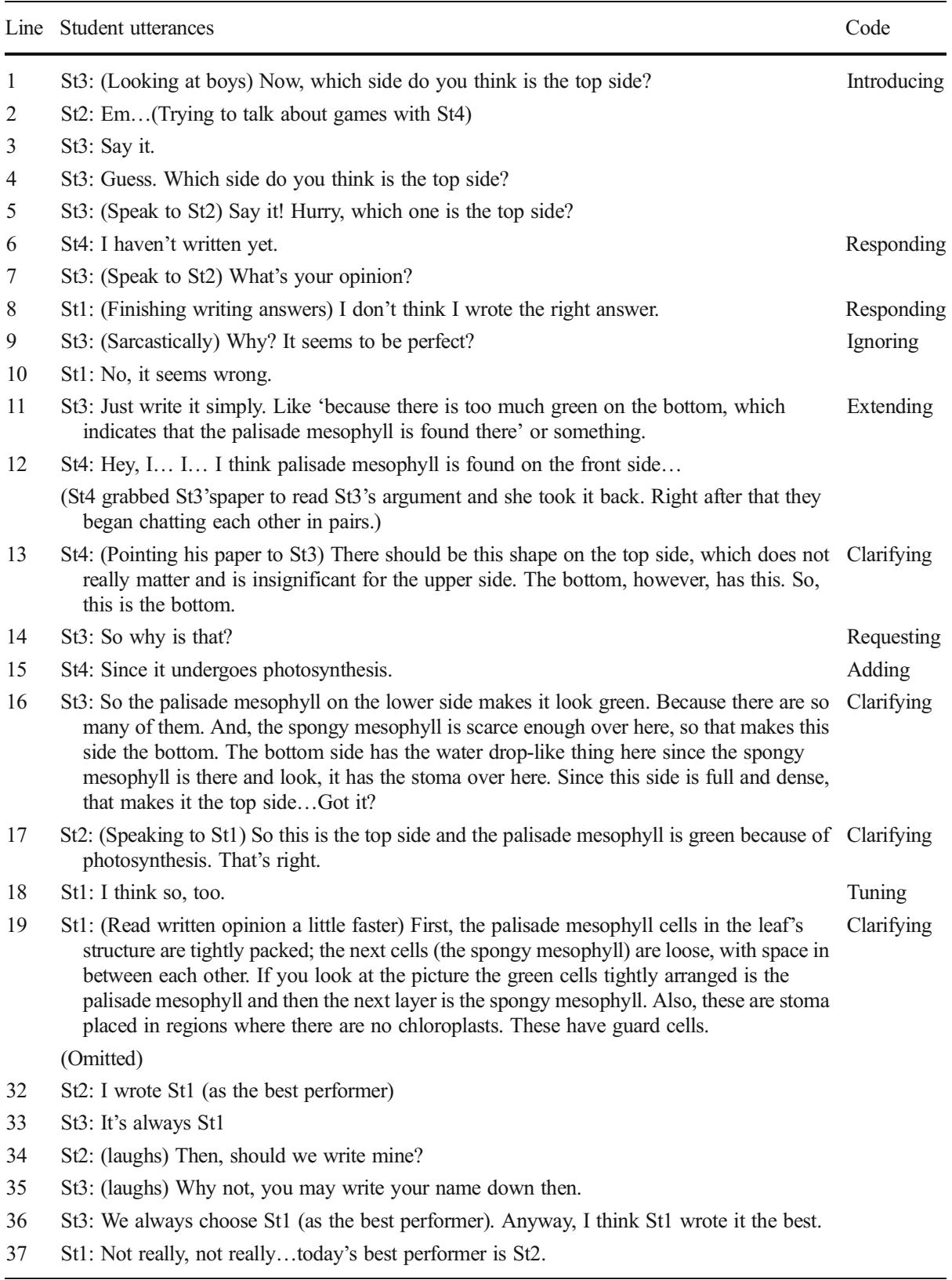

to voice their opinions by stating her own opinions (see line 11). Accordingly, St4, who was previously passive, tried to explain his idea to St3, who asked an additional question to clarify and justify his opinion (see lines 13-16). St2 also stated his opinions, such as noting that since palisade mesophyll is green, he could conclude which side is the top side by noting that palisade mesophyll is involved in photosynthesis (see line 17). St1 approved his opinion, saying, 'Today's best performer is St2' (see line 37) and considered his answers the most 
convincing. All four students showed clarified utterances with adequate evidence and then shared their opinions in pairs.

We believe that this participation shift was caused by two things: (1) the features of the topics in lesson eight and (2) the change in small group norms. The tasks in lesson 8 involved more critical thinking skills compared to the tasks that were geared towards retrieving the right answer. Students were able to support their claims based on various forms of evidence that they had collected. Stl's lack of confidence ('I don't think I wrote the right answer') provided opportunities for other students to present their opinions. We observed discourse activity among students without the teacher's directives, which showed that students had formed a norm of understanding the importance of participating in sharing their claims with others. During previous lessons, the teacher continually emphasised that, 'The important thing is writing down your own opinion; there is no one correct answer. You should all talk about your thoughts with the others.' We assume that the teacher's encouragements brought about the change in how students interacted with one another. We noticed, in lesson 8, that students began showing a level of respect for one another in the class. St2, who was initially neglected, began to participate and gain confidence in verbally sharing his claims with other group members.

The task of the 12th lesson was about predicting what would happen in a petri dish containing spirogyra and aerobic bacteria when it was placed such that half was in the light and the other half in the shade. In this lesson, group discussion was also initiated by St3 asking and collecting other members' opinions. St3 again took on the role of leader. One notable change was that St2 started to argue about choosing the most convincing opinions. Unlike in the early lessons, he became more active and willing to present his opinions. When St1 said St3's opinion was the best, St2 objected to St1's acceptance of St3's argument without examining other peers' arguments. Consequently, St3 gave St2 a chance to talk about his argument and asked St1 to pay attention to him. St2 then produced a series of clarified utterances to justify his claim that 'aerobic bacteria move to the light' by providing evidence, such as 'oxygen concentration is higher in the light than in the dark', backed up by the knowledge that 'spirogyra release oxygen through photosynthesis in the light' and 'spirogyra absorb oxygen and emit carbon dioxide in the dark'. Therefore, in the later lessons, all group members stated their opinions, and even St2 and St3, who were low-achieving students, showed the characteristics of full participants (Lave and Wenger 1991).

\section{Social Norms}

There were changes in terms of social norms in this group. The biggest change was that students started to discuss without the teacher's initiation of discussion, which they had not done in the early phase. Moreover, the person who initiated discussion changed from the highachieving student, St1, to a low-achieving student, St3. During the group discussion, she took the role of host to direct discussions, suggesting not only to St1 but also to the two other students that they present their opinions. This shows that the other students acknowledged St3 as a leader in the group. A second change was that the normative understanding that 'anyone's opinion is valuable and we can learn from one another' was revealed. For instance, St3 said in her interview, 'When I saw the boys, I had a feeling that if I didn't present my opinions then they would not say anything either. So I tried to say more, because I believed it would be better to learn with the other members.' From this attitude, we can deduce changes in her beliefs about peers' roles in a group. In earlier lessons she adopted St1's opinion while ignoring other members' opinions, but in later lessons she began to place value on sharing opinions with others. As a result, the discussion atmosphere changed greatly, with the consequence that students were able to develop group arguments together. 


\section{Argumentation Norms}

Students showed the normative understanding that would govern their reasoning for argumentation. First, students perceived argumentation as the process of justifying their claims and realised that connecting claims with evidence was important. Students who had tried to find a correct answer changed their attitude. They presented their own claims spontaneously, secure in the belief that they did not need to find only one correct answer. St 4 expressed this belief that was reflected in his behaviour at the interview, saying, 'I wrote down claims in my own way because the teacher said there was no one right answer.' Furthermore, students requested that their peers justified their claims by providing evidence. For example, in the eighth lesson, St3 asked St4 to justify his claim using reasons drawn from his knowledge of leaf structure and function, saying, 'So, why is that?' Consequently, all students presented their claims with evidence and tried to persuade their peers that their arguments were valid. Second, they became aware of the importance of presenting ideas and evaluating which argument was more valid when choosing an argument within a group. This change in perception was also seen in the discourse where students tried to choose the best argument. In the eighth lesson, St2's argument was chosen as the best one because he convinced peers of its validity by presenting a series of reasons. It was a significant change from the earlier lessons, when St2 had mostly been ignored by peers. Another example emerged from the 12th lesson, when St2 was not pleased that St1 accepted St3's argument without offering other students any chance to justify their own arguments. He proposed that all members' arguments should be heard and his suggestion was accepted. Last, students were complimented by other members when they tried to state opinions based on given or experimental data, showing that they were able to present in a way that was respected by others in the group.

The same patterns of argumentation norms were found in St1's daily life outside science class. When she was asked what had changed since she had begun to participate in the argumentation activities, she answered, 'Previously, I just memorised information without questioning its veracity. But after [participating in] these activities, I just write everything down like this, and then I keep reviewing...I compare answers with my friend. When we have different answers, I say, "I think this way, but why do you think that way?" I didn't care about others' wrong answers before...' This interview revealed a change in St1's norms via argumentation. In the case of scientific inquiry, high level argumentation consists of justifying a claim based on valid evidence, evaluating one's own argument and being able to refute opposing claims. We noticed that St1 showed her understanding of the argumentation norms and her ability to apply them in different situations. Table 5 summarises the changes in group norms in small group argumentation.

\section{Discussion}

In this study, it is significant that collaborative argumentation occurred in an authoritative Korean classroom context, where students have historically been reluctant to discuss or express their ideas in a class or group. The changes in students' participation and group norms did not take place as soon as we introduced new teaching and learning strategies for enhancing students' argumentation skills into science classes. In the early phase of this study, the highachieving student, St1, was the only one who stated her opinion, while the other three did not. However, in the later phase of the study, more students presented their own ideas and showed active participation in group argumentation. The results indicate that differences in the level of students' participation diminished, and the status of the students in the group became more 
Table 5 Changes of small group norms

\begin{tabular}{|c|c|c|c|}
\hline \multicolumn{2}{|l|}{ Dimension } & \multirow{2}{*}{$\begin{array}{l}\text { Earlier lessons } \\
\text { - Students should start the discussion } \\
\text { when the teacher asks them to. } \\
\text { - The high-achieving student has to } \\
\text { lead the discussion. }\end{array}$} & \multirow{2}{*}{$\begin{array}{l}\text { Later lessons } \\
\text { - Discussions can be initiated } \\
\text { without the permission of the } \\
\text { teacher. } \\
\text { - A low-achieving student can } \\
\text { lead the discussion. }\end{array}$} \\
\hline Social norms & Leading discussion & & \\
\hline & $\begin{array}{l}\text { Mean-making in } \\
\text { a group }\end{array}$ & $\begin{array}{l}\text { - A high-achieving student has to } \\
\text { present his/her opinion. } \\
\text { - If I don't know what to say, it } \\
\text { would be better to be quiet. }\end{array}$ & $\begin{array}{l}\text { - My opinion is also valuable and } \\
\text { respected by others. } \\
\text { - Opportunities should be given } \\
\text { to everyone. } \\
\text { - We can learn from one another. }\end{array}$ \\
\hline \multirow[t]{2}{*}{$\begin{array}{l}\text { Argumentation } \\
\text { norms }\end{array}$} & $\begin{array}{c}\text { Goal of scientific } \\
\text { argumentation }\end{array}$ & $\begin{array}{l}\text {-We have to find out the right } \\
\text { answer that the teacher expected. } \\
\text {-We can select any idea to be a } \\
\text { representative idea of our group. }\end{array}$ & $\begin{array}{l}\text {-It is important to present my } \\
\text { claim with evidence. } \\
\text { - We should choose the best } \\
\text { argument by evaluating each } \\
\text { argument. }\end{array}$ \\
\hline & Justifying claims & $\begin{array}{l}\text {-Someone's argument is correct if } \\
\text { it contains knowledge presented } \\
\text { in the textbook. } \\
\text { - Common sense or analogies can } \\
\text { be evidence. }\end{array}$ & $\begin{array}{l}\text { - It is valid and acceptable to } \\
\text { argue based on experimental } \\
\text { data and scientific knowledge. } \\
\text { It is valid to explain scientific } \\
\text { phenomena relying on the } \\
\text { interpretation of given data. }\end{array}$ \\
\hline
\end{tabular}

equal, as the previously dominant high-achieving student now shared more opportunities for her peers to present their opinions.

Some factors seemed to help improve students' participation and build social norms and argumentation norms in this group (Fig. 1).

First, tasks developed for this study created opportunities for students to practise argumentation, which required them to express their ideas based on evidence. While students were solving problems in the tasks, it was expected that they would justify their claims and describe the criteria they used to evaluate their peers' ideas. Moreover, non-valid, evidence-based claims used as sample statements in the tasks played a role in developing the practice of small group argumentation. For example, in lesson 4, the invalid sample claim (a plant needs potassium, iron, sodium and chloride to grow) was given to students as an example of presenting claims based on evidence collected. This example gave students a visual understanding of the need for evidence to support their judgment on why their claim was right or wrong. Students compared plants A-D, recognised the different growth of each and discussed which element was the influential factor for such growth results. Based on the example presented, students refuted the claims offered. For instance, the experimental result for plants A and D showed that there was no difference in growth, although the sample claim did not support this experimental result. This invalidly structured statement prompted students' cognitive conflict and stimulated them to provide alternative claims or arguments and refute invalid claims. In this process, students asked for additional evidence from others. These discourses might reflect the development of the argumentation norms in a group.

Second, the teacher gave metacognitive questions to the students and continually stressed the importance of presenting their own opinions. At the beginning of the research, every time the teacher observed most students not writing down their thoughts, hesitating or looking for the answers in the textbook, rather than brainstorming their own ideas, the teacher would say, 'There is no correct answer. The important thing here is writing down your own opinion and 


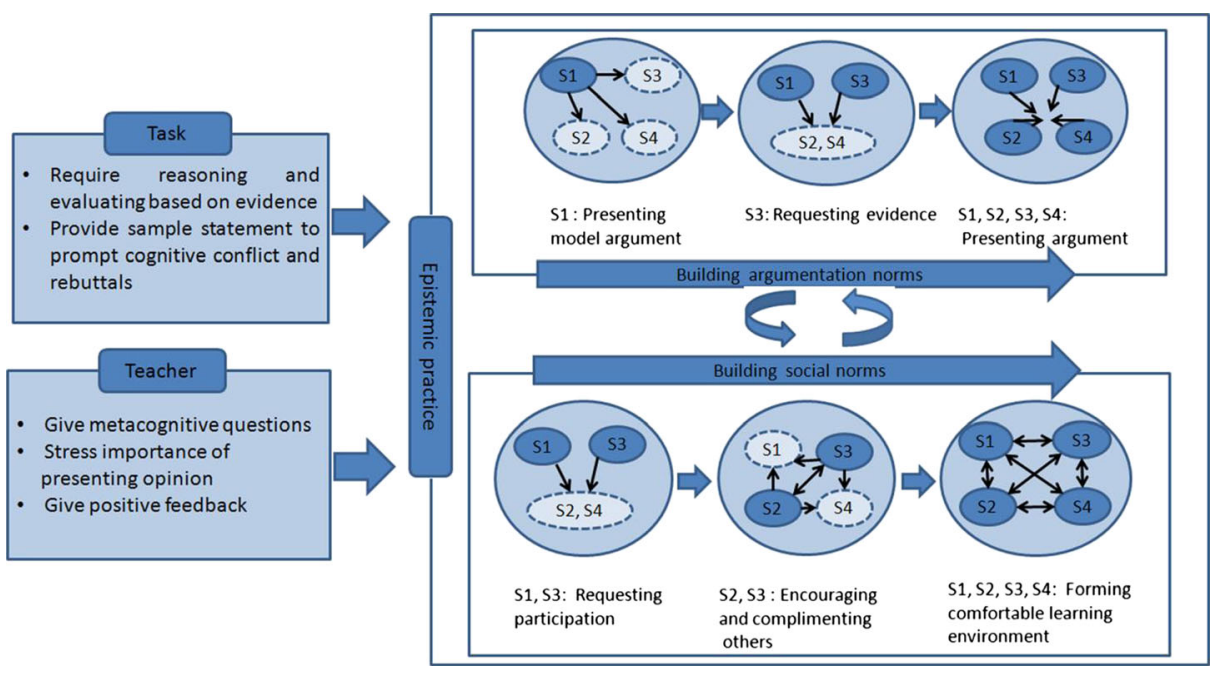

Fig. 1 Factors influencing a change in students' participation and building group norms

being able to reasonably and logically explain it with evidence as support. This is what we're looking for.' The teacher constantly reiterated this message. Near the end of the research, she encouraged students to explain the reasons for their claims and gave positive feedback to the students who had built arguments based on evidence, even if the student did not give an expected answer. Thus, the teacher helped students construct arguments by emphasising the social and argumentation norms implicitly and explicitly.

Third, students' talk in small group discussion contributed to establishing the argumentation norms and to enhancing epistemic practice. Students seemed to learn how to argue by hearing other members' arguments, which included evidence. In our study, a high-achieving student, St1, presented her claim based on evidence involving experimental results or scientific knowledge during the earlier lessons, at a time when other students were not yet demonstrating this practice. She modelled what it looked like to make an argument using evidence or to ask peers to reason with others, a role teachers took in the study of Berland and McNeill (2010). As small group discussion progressed, a low-achieving female student, St3, spontaneously began to ask the boys in the group to offer additional evidence to back up their claims. The contributions to the discussion of these two students, St1 and St3, established a supportive environment that was important for developing the argumentation norms by which an individual's idea or reasoning should be presented. As a result, all students showed discourse characteristics reflecting the argumentation norm by asking their peers to justify their claims using evidence or evaluating their arguments. Thus, a peer's utterance provided epistemological and cognitive support in small group argumentation that led to building argumentation norms and practice, which required students to use valid evidence and reasoning rather than just to express simple knowledge.

Finally, students' affective support forced a shift in participation. For example, St1 and St3 tried to lead the other students to talk about their opinions when they saw them chatting. In particular, St3, a low-achieving student, encouraged her peers who were reluctant to present opinions and also played a leading role in the later phase of lessons, in which the two boys complimented St3 on her plausible opinions. With St1 and St3's effort and support, a comfortable atmosphere was created, where every student was expected to participate in the discussion and to respect his or her peers' opinions. In addition, it was expected in science classes that anyone in a group could initiate a discussion, even though she or he was a low- 
achieving student. Self-confidence increases when students receive encouragement and compliments from peers, and this may account for the improved atmosphere during group argumentation, which was found to lead to the building of new social norms that fostered collaborative learning. Like a number of studies that stress the importance of a permissive atmosphere in small group argumentation (Dixon et al. 2009; Mortimer and Scott 2003; Park and Kim 2012), our study showed that students gain confidence and become active in group discussions by complimenting and encouraging each other.

The teacher presented a task that prompted argumentation and continually stressed the importance of presenting one's own opinions, thereby encouraging students to articulate their scientific knowledge to organise their argument and to persuade other members in a group through argumentation. During a 4-week period, most students in this group showed an improved level of argument and academic achievement (Table 6). In particular, St2 showed a huge improvement in participation and in constructing an argument involving his claim, evidence and reasoning on his post-test, whereas on the pre-test, he had presented only claims. St2 also achieved a higher post-test score than his pre-test, showing that he thoroughly understood the concept. The practice of collecting evidence for argumentation fed into an increase in his scientific knowledge, which eventually raised his overall understanding of photosynthesis. Therefore, he improved his standing (from 50th to 15th percentile of all the students) in science achievement.

\section{Conclusion and Implications}

In this paper, we interpreted students' participation in terms of social and argumentation norms. We analysed students' participation and inferred group norms from students' discourse and behaviour. As lessons progressed, students gradually moved from peripheral participation to full participation and in the later phase, offered clarifying opinions. Group norms also changed from an authoritative environment, where utterances were produced by the teacher or a highachieving student, to a permissive environment, where more students' opinions were valued. The students became aware of the purpose of argumentation and supported their arguments with evidence, such as scientific knowledge and experimental data, rather than searching for answers in textbooks. The changes in students' participation were enabled by changes in group norms. We explained changes in students' participation and small group norms based on four factors: (1) Tasks developed by researchers helped students construct their argument by considering various evidences and making sure there is a connection with a claim to refute the invalid sample statement provided; (2) the teacher's role was essential because she emphasised the importance of making an argument based on evidence and also prompted group discussions in the class; (3) students' support in argumentation lead to changes in group norms by highlighting

Table 6 Pre-test and post-test achievement score of photosynthesis and students' argument level

\begin{tabular}{lllllll}
\hline & & Mean score of the class & St1 & St2 & St3 & St4 \\
\hline \multirow{2}{*}{ Achievement score } & Pre & 28.9 & 70 & 20 & 10 & 10 \\
& Post & 61 & 90 & 80 & 60 & 20 \\
\multirow{2}{*}{ Argument level } & Pre & - & C, E, R & C & - & E \\
& Post & - & C, E & C, E, R & C, E, R & C, E, R \\
\hline
\end{tabular}

Total score 100

$C$ claim, $E$ evidence, $R$ reasoning 
the necessity of evidence to support a claim and present an opinion, exemplifying how to construct an argument; and (4) students' encouragement supported a collaborating group atmosphere by complimenting and praising others when valid opinions were presented in a group; this encouragement led to greater levels of student participation.

We focused on one group among eleven small groups to analyse argumentation. The findings of our study could not lead to the conclusion that all small group argumentation will show similar results. Nevertheless, we intended to seek ways of changing students' participation and group norms in class, as well as figuring out how different factors have an effect on these changes, by focusing on the group that showed the most active participation. Although our study is subject to some limitations, it provides valuable insights into how students' argumentation has been changed in the classroom setting in relation to small group norms.

Although there has been much research highlighting the benefits of implementing argumentation in a classroom, one reason for the difficulty in implementing argumentation is the lack of class time. Taking this into consideration, we inserted 15 to 20 minutes for argumentation into a 45 minute science lesson so that the teacher could explain the scientific concept followed by small group work. This could reduce the burden on the teacher in relation to the time limitation, while implementing a new teaching strategy into the lesson. We also offered relatively sufficient opportunities for students to experience argumentation by the construction of the 12 lessons. We think our research can be an example of successful student participation influencing a change in group norms through short experiences instead of whole argumentation lessons.

Although the importance of students' participation in a class was stressed, many teachers still assume power and control over interactions taking place in class. In addition to the dominant role of the teacher, the power structure in student group culture does not seem to be fair. A number of studies have pointed out the challenges associated with establishing collaborative learning environments (Bianchini 1997; Kelly and Crawford 1997; Moje and Shepardson 1998). For example, group discussions are frequently dominated by the most outspoken and advantaged individuals in the group context, whose opinions tend to prevail. The status of students is closely associated with their participation: The higher-status student is able to make more contributions and thus to acquire much more knowledge (Bianchini 1997). Therefore, norms and culture must be developed in such a way that all students can participate and have ownership of their learning in the classroom. However, studies have not suggested the norms that should be established to prompt students' participation. We have identified two types of norms formed in a group by analysing small group argumentation: social norms and argumentation norms. Also, the norms established in later lessons in this research led to active participation of students. Thus, the social norms and argumentation norms we identified can provide insights into a way of prompting argumentation for science teachers and science educators. To create a permissive atmosphere for participation, schools should enable students to learn how to argue and build scientific argumentation norms. Many researchers have cited the need to foster argumentation skills and abilities of teachers as well as students (Chin and Osborne 2010; Hogan 1999; Jiménez-Aleixandre et al. 2000; Roth and Roychoudhury 1992). Thus, teachers and students should work together to create an environment in which classroom norms and culture are established, encouraging students to take responsibility for their learning and learn how to construct and express their knowledge.

There were dramatic improvements in scientific achievement and argument construction in our selected focus group. These improvements show that it is possible to enhance students' competence to construct an argument and understand scientific concepts by implementing argumentation. This study has positive implications for suggesting how to; support students to construct an argument, encourage low-achievers to participate in argumentation activities and acknowledge the importance of the teacher's support, group members' cognitive support and social interaction. 
Acknowledgments This work was supported by the National Research Foundation of Korea Grant funded by the Korean Government (NRF-2012S1A5A2A01019966). The opinions expressed in this work are those of the authors and not necessarily those of the NRF.

\section{Appendix Task Example}

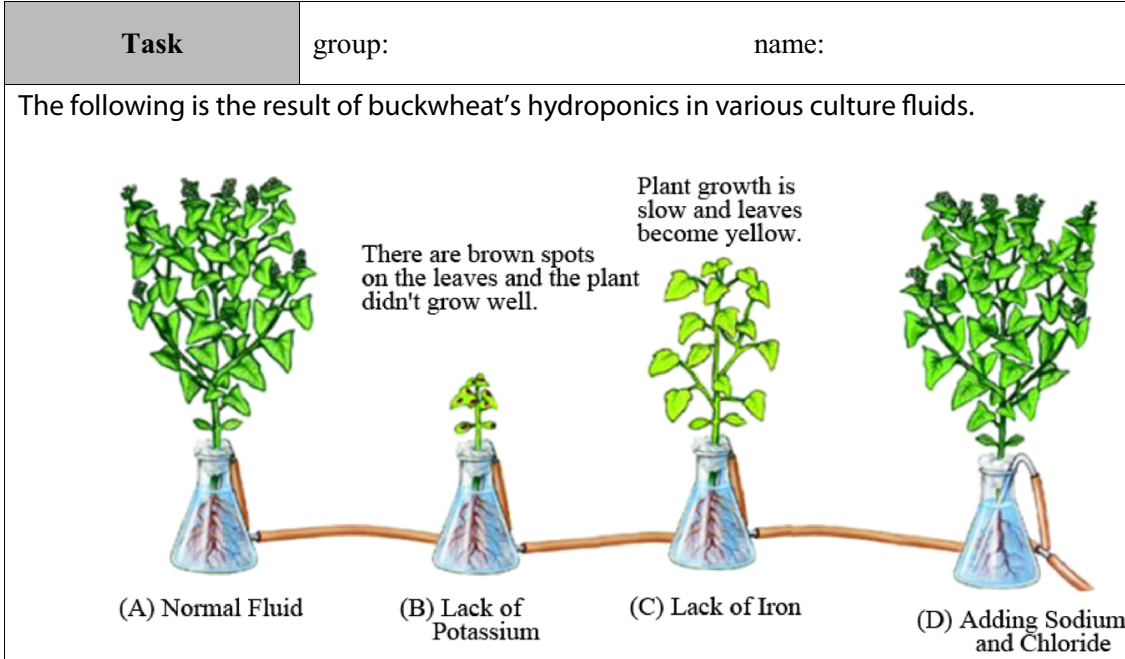

When looking at the results of this experiment, someone said, 'A plant needs potassium, iron, sodium and chloride to grow.'

Do you agree or disagree?

My opinion

Provide adequate reasons why you agree or disagree.

What are the opinions of the others in your group?

Agreement:

Disagreement:

Compare with others

Try to give reasons to persuade the people that oppose/disagree with you.

Write down the most plausible opinion in your group. 
Open Access This article is distributed under the terms of the Creative Commons Attribution License which permits any use, distribution, and reproduction in any medium, provided the original author(s) and the source are credited.

\section{References}

Anderson, K. T., Zuiker, S. J., Taasoobshirazi, G., \& Hickey, D. T. (2007). Classroom discourse as a tool to enhance formative assessment and practice in science. International Journal of Science Education, 29(14), 1721-1744.

Bennett, J., Hogarth, S., Lubben, F., Campbell, B., \& Robinson, A. (2010). Talking science: the research evidence on the use of small group discussions in science teaching. International Journal of Science Education, 32(1), 69-95.

Berland, L. K., \& McNeill, K. L. (2010). A learning progression for scientific argumentation: understanding student work and designing supportive instructional contexts. Science Education, 94(5), 765-793.

Berland, L. K., \& Reiser, B. J. (2009). Making sense of argumentation and explanation. Science Education, 93(1), 26-55.

Bianchini, J. A. (1997). Where knowledge construction, equity, and context intersect: student learning of science in small groups. Journal of Research in Science Teaching, 34(10), 1039-1065.

Blatchford, P., \& Baines, E. (2010). Peer relations in school. In K. Littleton, C. Wood, \& J. K. Staarman (Eds.), International handbook of psychology in education (pp. 227-274). UK: Emerald Group Publishing.

Chin, C., \& Osborne, J. (2010). Students' questions and discursive interaction: their impact on argumentation during collaborative group discussions in science. Journal of Research in Science Teaching, 47(7), 883-908.

Dixon, J. K., Egendoerfer, L. A., \& Clements, T. (2009). Do they really need to raise their hands? Challenging a traditional social norm in a second grade mathematics classroom. Teaching and Teacher Education, 25(8), 1067-1076.

Driver, R. (1995). Constructivist approaches to science teaching. In L. P. Steffe \& J. Gale (Eds.), Constructivism in education (pp. 385-400). Hillsdale: Lawrence Erlbaum.

Driver, R., Newton, P., \& Osborne, J. (2000). Establishing the norms of scientific argumentation in classrooms. Science Education, 84(3), 287-312.

Duschl, R. A. (2008a). Quality argumentation and epistemic criteria. In S. Erduran \& M. P. Jiménez-Aleixandre (Eds.), Argumentation in science education: perspectives from classroom-based research (pp. 159-175). Dordrecht: Springer.

Duschl, R. A. (2008b). Science education in 3 part harmony: balancing conceptual, epistemic and social goals. Review of Research in Education, 32, 268-291.

Duschl, R. A., Ellenbogen, K., \& Erduran, S. (1999) Promoting argumentation in middle school science classrooms: a project SEPIA evaluation. Paper presented at the annual meeting of the National Association for Research in Science Teaching, Boston, MA

Duschl, R. A., Schweingruber, H. A., \& Shouse, A. W. (Eds.). (2007). Taking science to school: learning and teaching in grades $K-8$. Washington, DC: National Research Council.

Erduran, S., Simon, S., \& Osborne, J. (2004). TAPping into argumentation: developments in the application of Toulmin's Argument Pattern for studying science discourse. Science Education, 88(6), 915-933.

Hogan, K. (1999). Thinking aloud together: a test of an intervention to foster students' collaborative scientific reasoning. Journal of Research in Science Teaching, 36(10), 1085-1109.

Hogan, K., \& Maglienti, M. (2001). Comparing the epistemological underpinnings of students' and scientists' reasoning about conclusions. Journal of Research in Science Teaching, 38(6), 663-687.

Jiménez-Aleixandre, M. P., Rodríguez, A. B., \& Duschl, R. A. (2000). 'Doing the lesson' or 'doing science': argument in high school genetics. Science and Education, 84, 757-792.

Kelly, G. J., \& Crawford, T. (1997). An ethnographic investigation of the discourse processes of school science. Science Education, 81(5), 533-559.

Kelly, G. J., Chen, C., \& Crawford, T. (1998). Methodological considerations for studying science in the making in educational settings. Research in Science Education, 28(1), 23-49.

Lave, J., \& Wenger, E. (1991). Situated learning: legitimate peripheral participation. Cambridge: Cambridge University Press. 
McNeill, K. L. (2009). Teachers' use of curriculum to support students in writing scientific arguments to explain phenomena. Science Education, 93(2), 233-268.

Moje, E. B., \& Shepardson, D. P. (1998). Social interactions and children's changing understanding of electric circuits. In B. J. Guzzetti \& C. Hynd (Eds.), Perspectives on conceptual change: multiple ways to understand knowing and learning in a complex world (pp. 225-234). Mahwah, NJ: Erlbaum.

Mortimer, E. F., \& Scott, P. (2003). Meaning making in secondary science classrooms. Buckingham: Open University Press.

Newton, P., Driver, R., \& Osborne, J. (1999). The place of argumentation in the pedagogy of school science. International Journal of Science Education, 21(5), 553-576.

Nussbaum, E. M., \& Bendixen, L. M. (2003). Approaching and avoiding arguments: the role of epistemological beliefs, need for cognition, and extraverted personality traits. Contemporary Educational Psychology, 28, 573-595.

Nussbaum, E. M., Sinatra, G. M., \& Poliquin, A. (2008). Role of epistemic beliefs and scientific argumentation in science learning. International Journal of Science Education, 30(15), 1977-1999.

Park, J., \& Kim, H. (2012). Theoretical considerations on analytical framework design for the interactions between participants in group argumentation on socio-scientific issues. Journal of the Korean Association for Research in Science Education, 32(4), 604-624.

Piaget, J. (1977). The development of thought: equilibration of cognitive structures. Oxford, UK: Viking Press.

Richmond, G., \& Striley, J. (1996). Making meaning in classrooms: social processes in small-group discourse and scientific knowledge building. Journal of Research in Science Teaching, 33(8), 839-858.

Roth, W.-M., \& Lawless, D. (2002). Science, culture, and the emergence of language. Science Education, 86(3), 368-385.

Roth, W.-M., \& Roychoudhury, A. (1992). The social construction of scientific concepts or the concept map as conscription device and tool for social thinking in high school science. Science Education, 76(5), 531-557.

Roth, W.-M., McGinn, M. K., Woszczyna, C., \& Boutonné, S. (1999). Differential participation during science conversations: the interaction of focal artifacts, social configurations, and physical arrangements. The Journal of the Learning Sciences, 8(3\&4), 293-347.

Ryu, S., \& Sandoval, W. A. (2012). Improvements to elementary children's epistemic understanding from sustained argumentation. Science Education, 96(3), 488-526.

Sampson, V., \& Clark, D. B. (2008). Assessment of the ways students generate arguments in science education: current perspectives and recommendations for future directions. Science Education, 92(3), 447-472.

Sandoval, W. A., \& Millwood, K. A. (2005). The quality of students' use of evidence in written scientific explanations. Cognition and Instruction, 23(1), 23-55.

Toulmin, S. E. (1958). The uses of argument. Cambridge: Cambridge University Press.

Vygotsky, L. S. (1980). Mind in society: the development of higher psychological processes. Cambridge: Harvard University Press.

Watson, J. R., Swain, J., \& McRobbie, C. (2004). Students' discussions in practical scientific inquiries. International Journal of Science Education, 26(1), 25-45.

Weinstock, M., Neuman, Y., \& Tabak, I. (2004). Missing the point or missing the norms? Epistemological norms as predictors of students' ability to identify fallacious arguments. Contemporary Educational Psychology, 29, 77-94.

Yackel, E., \& Cobb, P. (1996). Sociomathematical norms, argumentation, and autonomy in mathematics. Journal for Research in Mathematics Education, 458-477

Yerrick, R. K. (2000). Lower track science students' argumentation and open inquiry instruction. Journal of Research in Science Teaching, 37(8), 807-838. 